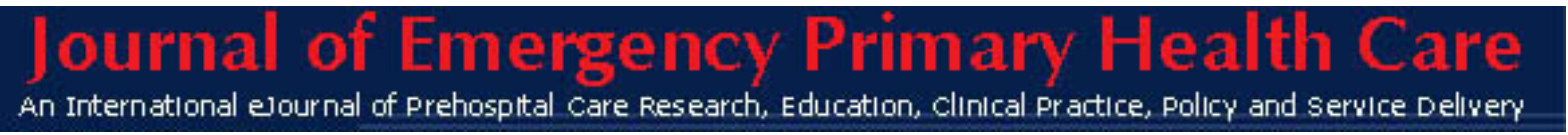

ISSN 1447-4999

\title{
EDUCATION
}

\section{Getting Ethics Committee Approval for Research: A Beginners Guide}

\author{
Amee Morgans - PhD Scholar \\ Monash University Centre for Ambulance and Paramedic Studies \\ and \\ Associate Professor Felicity Allen \\ School of Psychology, Psychiatry and Psychological Medicine \\ Monash University
}

Article No. 990077

\begin{abstract}
The process of gaining ethics approval is an essential step in conducting research. This paper acts as a beginners guide to the process of ethics approval for first time and student applicants, and offers some tips to planning for ethics approval as part of the research methodology to minimise any potential revisions the ethics committee may request. The paper also briefly discusses how seeking ethics approval can improve research practices and benefit research design.
\end{abstract}

Keywords: ethical issues; ethics; ethics approval; ethics committees; informed consent; research.

Ethics committees for research involving humans have a vital role in protecting researchers, participants, and the wider community. The purpose of an ethics committee (EC) is to ensure that research is conducted in accordance with prevailing moral standards and humane practices, with minimal risk to participants. ${ }^{1}$ Ethics Committees can be found at most health and research organisations, and each committee is comprised of a broad range of volunteer adjudicators including lay people, religious and cultural representatives in addition to medical, research and legal representatives. ${ }^{1}$ Ethics committees assess research in the context of many ethical concepts, and address common ethical issues encountered in research, such as potential participant coercion, informed consent and participants' decision-making capacity. The overall role of the ethics committee is to balance the potential benefit of the research to the community against the potential risk of harm or inconvenience to the participant.

The typical process of application requires the research team to send a completed application form to the ethics committee. Most research requires that participants give informed consent, and therefore researchers must also provide their plain language statement and consent forms to the ethics committee. Typically the application covers the recruitment method, research design and participant requirements. Once the application is received, it is read by some 
members of the ethics committee who highlight any ethical issues or areas requiring clarity, according to a national set of guidelines ${ }^{1}$. These questions are posed to the researchersometimes by letter and sometimes in an interview which the researcher is required to attend, and once they have been addressed to the committee's satisfaction and are within the national guidelines, the research is approved.

The importance of ethics committees was demonstrated in a survey sent to research teams in New Zealand, which found that half of the participants responded favourably on most aspects of EC functioning, however, half also reported occasions where they felt the approval process unnecessarily impeded research, usually by delays and costs. ${ }^{2}$ Although researchers commonly lament the length of time required to obtain ethics approval, one UK study addressed the actual causes of approval delays, and found that most were caused by the researchers failing to provide enough information to the EC, researchers filling out forms incorrectly and providing poorly worded information for participants. ${ }^{3}$ These two studies demonstrate that the frustration with ECs expressed in by the survey participants is not based in its consideration of the proposals ethical merit, but rather is usually attributable to the length of time taken to process the application, which then has the potential to delay research activities ${ }^{4}$.

It is important that researchers understand the reasons for delays and costs, and learn how these can be avoided. The activities of ECs over the past 20 years have been influenced by the increase of legal and bureaucratic developments, and now face a situation where ECs in Australia are overwhelmed with new and changing guidelines and legislation and are being heavily depended on to perform research governance activities in addition to guidance on ethical issues. ${ }^{5}$ This affects not only researchers, who now have to fulfil more requirements to get approval, but also the EC, which has to ensure that all requirements have been met. Ethics application forms and approvals have become more complicated, which is the direct result of changes in legislation, particularly the changes in privacy laws. ${ }^{6,7}$ It is important to keep in mind that these changes are aimed at increasing protection for participants and research teams alike, and consideration of the legislation affecting research activities should be part of good research design. Because of the essential process of obtaining ethics approval, it is important that researchers consider how much time this will take, and account for this when building a timeframe to complete their research. An ethics committee will need time to circulate the application to its members, who will then consider it, generally followed by a meeting based discussion. This process takes time, which researchers need to be prepared for, particularly $\mathrm{n}$ the areas of prehospital and emergency research, where the participants are considered to be highly vulnerable.

One common cause of delay arises when ethics approval is required from multiple locations. In some cases, it is important to conduct research at more than one health facility or location to eliminate clinic or practitioner bias, or simply in the interests of recruiting an adequate sample when a condition or intervention is rare. This methodology is referred to as multicentre research. The National Statement on Ethical Research released in $1999^{1}$ stated that the ethical and scientific assessment of one committee could be accepted at other sites. This is rarely the case in most research sites in Australia $^{7}$ or overseas ${ }^{8}$ even when adequate provisions are in place. What this means is that currently most multi-centre trials require applications to the ECs of all sites where the research will be conducted, as illustrated in a West Australian state-wide investigation into prostate cancer, which necessitated application to 29 ECs, despite State Government Department of Health approval. ${ }^{9}$ This demonstrates the need to communicate with all participating health facilities early in the research design, to determine their needs and ensure that these form part of the submitted research design. 
Getting approval at one ethics committee can be difficult enough, but in multicentre research trials the difficulties are multiplied by the number of sites and therefore approvals that are required. In some research designs, this can mean applications at multiple health care facilities, and often on application forms unique to each health facility, ${ }^{10}$ requiring repetitive documentation and sometimes resulting in clashes between approval conditions of diverse committees, primarily relating to resource availability and policy issues. In Victoria, there has been some recent collaboration between Monash University and Southern Health who have implemented a mutual approval system, where approval at one committee is granted on behalf of both bodies, thereby cutting approval time in half. Similar initiatives are being trialled in the UK, where a multi-centre EC has been formed, whose recommendations are then sent on to an executive subcommittee of the proposed sites; referred to as a "local" committee $^{11}$. The local executive subcommittee has a quorum of 2 members, meets more frequently than the full local EC, and provides expedited approval wherever possible. Although this system is still in its infancy and has some flaws, ${ }^{12}$ it is a move by ECs toward minimising ethics associated cost and delay in multi-centre research.

Researchers need to understand that the causes of delay arise from legislation aimed for their own protection and that of their participants, and not from ECs. Researchers need to find a way to work with ECs, rather than seeing them as an obstruction to research. If you do not have ethics approval, it only takes one complaint to bring the research - and potentially your career- to a grinding halt. Although in some cases there are unavoidable time delays and costs, there are things that researchers can do to minimise the impact of the ethics application on the research process.

\section{Helpful Hints for Applications to Human Ethics Committees:}

\section{When do I need Ethics Approval?}

Australian law states that you have to get ethics approval for any activity that collects, uses or discloses information about any individual. ${ }^{13}$ You need ethics approval even if the participants are known to you, and are participating voluntarily, such as friends, family, coworkers or fellow students.

\section{Research Design}

As previously stated, the overall role of the ethics committee is to balance the potential benefit of the research to the community against the potential risk of harm or inconvenience to the participant. Therefore make sure the research design and the data that you plan to collect will achieve the project aims, and will answer the research question. This will ensure that the EC is able to easily identify the potential benefits and risks of the research you are proposing. In terms of constructing an ethical research methodology - think about it from the perspective of not only the potential participant, but how you would feel if that participant was you or someone important to you. Would you want them to be included in this research? Would the plain language statement give you enough information to make an informed choice? At the end of the day, all participants in research are someone's close friend or relative; and the next potential participant could be you.

\section{The Paper Chase}

In Victoria, there has been a move to using the Victorian Department of Human Services "Common Form"14 for all hospitals and health facilities. However, section 1 (of 5) alone is 25 
pages long, and that is before you start filling it out. Some health facilities offer their own "in house” EC application forms, which may be shorter. You will need to contact each organisation involved in the research and find out if ethics approval is required, and the closing dates for applications to the upcoming meetings. Most ECs meet fortnightly or monthly, so in some cases timing the application can save you a month. If possible, identify an actual person within the organisation who deals with ethics and keep a record of their email and phone details in case you have any questions, or want to call and ask about the process of your application.

In addition to the diverse application forms required for EC applications, applicants must be prepared for possible additional requirements each EC may have. Some hospital based ECs now charge an application fee. ${ }^{15}$ Although in most cases the fee is below $\$ 100$ before GST, ${ }^{15}$ in multicentre research this can add up to a prohibitive amount, ${ }^{16,17}$ and therefore should be budgeted for. Some other reported EC requirements are attendance at EC meetings, use of health facility letterhead, full written research protocols, literature search strategies and literature review, proposed budget, curriculum vitae of researchers, signed approval from hospital officials such as the directors of nursing, medicine and finance. Again, a contact at the EC can usually advise you on how best to fulfil these requirements.

Applicants to ECs should thoroughly research the requirements of each EC and get applications in as early as possible to avoid delay. Research budgets and proposals will need to allow for costs, including application fees. Project timelines need to allow for EC approvals, particularly in multicentre trials and in research designs that will require extensive ethical consideration.

\section{Consent, Communication and Coercion}

When writing an application to an EC, remember that ECs have a vital role in ensuring research being conducted is of minimal risk to participants. A common area of concern that arises when reviewing applications is the communication between researchers and potential participants.

In terms of communicating with the patient, a plain language statement should be exactly that - plain language - if your relatives can't read it and understand it, then it's too complicated. Many ECs provide templates for participant communications such as informed consent forms and plain language explanatory statements. Where a template is provided by an EC, use it! This minimises the workload to researchers and increases the likelihood that EC reviewers can use a checklist and identify clearly and quickly that you have fulfilled the EC requirements.

Most ECs require the researcher to provide the potential participant with a plain language statement of the project, which informs the participants of all the risks and outcomes, and allows them to make an informed decision to participate in the research. This decision to participate is called Informed Consent. The role of the EC is to make sure that the information that you are planning to give to participants is sufficient to allow them to make and informed decision. In many cases, the application is sent back to the researchers for amendment simply because the plain language statement is too complicated, contains jargon and assumes prior knowledge of research concepts. ${ }^{3}$ The other issue is the relationship between the person conducting the research and the participant - is there a dependent or unequal relationship? Coercion is a serious issue, and occurs when there is an unequal or dependant relationship between the researchers and the potential participants. Health professionals and patients, co-workers, teachers and students are all examples of this. The cries of 'my workers/patients/students/friends won't mind, it's just a survey' echo through the 
building during ethics interviews with researchers. You simply can't collect any type of information from another human being without suitable authority. Take a look at your methodology - is there some way that someone else could do the recruiting for you?

\section{Expedited Approval}

There are mechanisms in place at some ECs to allow for application for expedited approval. Expedited approval simply means that the project can be approved faster than normal applications. Examples of research that may be suitable for expedited review are review of information already collected, such as de-identified medical records or surveys. However, researchers should not depend on getting expedited approval. Criteria for projects that qualify for expedited approval vary between ECs and are usually assessed on a case by case basis. Advice should be sought from individual ECs.

Where research to be conducted is a short term project or student research, supervisors should consider making an ethics application as early as possible. Having ethics approval for a project before you have a student to conduct the research makes the project more attractive to potential students and is likely to decrease delays in student research, making the conduct of the project within postgraduate timeframes more realistic and less pressured. It is possible to make amendments to an ethics application once it has been approved, and amendments do not always have to go to a full committee meeting, they can occasionally be approved quickly by a senior member of the committee or a sub-committee, depending on the changes requested, and depending on the committee. For example, an amendment such as changing a question within a survey may be suitable for approval as an amendment; however changes to recruitment procedures may require consideration of the full committee. The processing of amendments varies greatly between committees, and advice should be sought from each committee as to their procedures for modifying a research proposal.

\section{More Information}

For Victorian applicants, there are volumes of information including a survival guide to completing the ethics application on the website for the Department of Human Services. ${ }^{18}$ For national Australian based potential applicants, the National Health and Medical Research Council (NHMRC) ${ }^{1}$ has information and links for state and national legislation regarding ethical conduct of research involving humans, including the nation wide Australian Health Ethics Committee. ${ }^{19}$

Researchers armed with a better understanding of EC processes will be more likely to get their project approved first time and with minimal amendments. Obtaining EC approval does take time; however, better preparation of applications will reduce the applicant-based errors making the whole experience more pleasant. Finally, researchers need to be reassured that EC approval is for their own protection from complaints and litigation, and should be seen as a positive step towards good research. 


\section{References}

1. Commonwealth of Australia. National Statement on Ethical Conduct in Research Involving Humans. Canberra, Australia: Commonwealth of Australia; 1999.

2. Paul C. Health researchers' views of ethics committee functioning in New Zealand. New Zealand Medical Journal 2000;113(1111):210-214.

3. Boyce M. Observational study of 353 applications to London multicentre research ethics committee 1997-2000. British Medical Journal 2002;325.

4. Wald DS. Bureaucracy of ethics committee applications. British Medical Journal 2004;329:282-284.

5. Walsh MK, McNeil JJ, Breen K. Improving the governance of health research. Medical Journal of Australia 2005;182(9):468-471.

6. O'Grady K-A, Nolan T. Privacy: Bad for your health? Medical Journal of Australia 2004;180:307.

7. Breen K, Hacker S. Comment: Privacy legislation and research. Medical Journal of Australia 2002;177(9):523-524.

8. Lux AL, Edwards SW, Osborne JP. Responses of local research ethics committees to a study with approval from a multicentre research ethics committee. British Medical Journal 2000;320(7243):1182-1183.

9. Jamrozik K, Kolybaba M. Are ethics committees retarding the improvement of health services in Australia? Medical Journal of Australia 1999;170:26-28.

10. Alberti KG. Local research ethics committees: Time to grab several bulls by the horns. British Medical Journal 1995;311(7006):639-640.

11. Tully J, Ninis N, Booy R, Viner R. The new system of review by multicentre research ethics committees: prospective study. British Medical Journal 2000;320(7243):11791182.

12. Alberti KG. Multicentre research ethics committees: has the cure been worse than the disease? No, but idiosyncracies and obstructions to good research must be removed. British Medical Journal 2000;320(7243):1157-1158.

13. Office of the Health Services Commissioner. Health Records Act 2001 (Vic): Statutory Guidelines on Research. Melbourne: Office of the Health Services Commissioner; 2002.

14. Department of Human Services, Common Application Form, Date Accessed; 21.04.2004, http://www.health.vic.gov.au/ethics/application/common_app_form.htm

15. Roberts LM, Bowyer L, Homer CS, Brown MA. Multicenter Research: negotiating the ethics obstacle course. Medical Journal of Australia 2004;180:139.

16. Dunn NR, Arscott A, Mann RD. Costs of seeking ethics approval before and after the introduction of multicentre research ethics committees. Journal of the Royal Society of Medicine 2000;93(10):511-512.

17. Crooks SW, Colman SB, Campbell IA. Costs and getting ethical approval deter doctors from participating in multicentre trials. British Medical Journal 1996;312(7047):1669.

18. Department of Human Services, Human Research Ethics Committee Home Page, Date Accessed; 3rd May 2004, http://www.health.vic.gov.au/ethics/index.htm

19. National Health and Medical Research Council of Australia, The Australian Health Ethics Committee, Date Accessed; 3rd May 2004, http://www.health.gov.au/nhmrc/ethics/ahec.htm

\section{Author Disclosure}

The authors have no financial, personal or honorary affiliations with any commercial organization directly involved or discussed in this study.

This Article was peer reviewed for the Journal of Emergency Primary Health Care Vol.3, Issue 3, 2005 